\title{
CURRICULUM MODIFICATIONS FOR TEACHING PARASITOLOGY AND INFECTIOUS DISEASES IN A BIOMEDICAL SCIENCE DEGREE
}

\author{
A. Peña-Fernández ${ }^{1}$, M. loannou' ${ }^{1}$, M.C. Lobo-Bedmar', S. Fenoy ${ }^{3}$ \\ ${ }^{1}$ Faculty of Health and Life Sciences, De Montfort University (UNITED KINGDOM) \\ ${ }^{2}$ IMIDRA, Departamento de Investigación Agroambiental (SPAIN) \\ ${ }^{3}$ Facultad de Farmacia, Universidad San Pablo CEU (SPAIN)
}

\begin{abstract}
Recent outbreaks threatening public health involving contaminated water or food with different microorganisms such as Escherichia coli or Cyclospora spp. in Europe as well as the 2014-16 Ebola crisis in West Africa have highlighted the relevance of teaching parasitology and infectious diseases to future biomedical scientists. The BSc Biomedical Science (BMS) programme at De Montfort University (DMU, Leicester, UK) is accredited by the Institute of Biomedical Sciences (IBMS). However, the dedicated time to study these topics was very little, limited to two 15 credit modules focused on general and basic medical microbiology. A series of important modifications have been undertaken since 2016 to ensure that our graduates receive comprehensive knowledge in parasitology/infectious diseases following the subject-specific threshold standards described by the Quality Assurance Agency (QAA, 2015). New lectures in these topics (virus, fungi, helminths, infectious diseases) were incorporated in our Basic Microbiology level 4 module after expanding this to 30 credits in the academic course 2016/17. Highly specialised training related with emerging parasites (e.g. Cyclospora, microsporidia) and haemorrhagic fever virus (e.g. Crimean-Congo Haemorrhagic Fever virus) was introduced in our level 6 Medical Microbiology module (15 credits), based on a successful novel teaching experience created by first responders to the Ebola outbreak in West Africa. Validated feedback questionnaires to assess the training were collected as well as final module level feedback (MLF) for each module through Blackboard. Students have highlighted high levels of engagement in both modules, specifically in the training provided in Medical Microbiology $(n=121)$. Thus, some students have highlighted in the MLF that the case studies (e.g. related with free-living amoebas and Cyclospora spp.) "improved my understanding" and were "engaging". The specific questionnaire highlighted that $77.5 \%$ of final year students enjoyed the novel workshop created to respond to an outbreak of infection affecting the UK following evidence-based public health methodology. However, the module that showed most improvement in student satisfaction was Basic Microbiology $(n=196)$, which showed a significant increase from $20 \%$ in the $2015 / 16$ academic year to $64 \%$ in the current academic session. The MLF for Basic Microbiology also reported the following results: $95 \%$ (41\% definitely agree, $54 \%$ agree) of students highlighted that this first year module provided them with opportunities to apply what they learnt; and $94 \%$ considered that the feedback provided was clear and fair. Although these results should be considered as preliminary, we consider that the initial changes undertaken in the BMS programme at DMU to date could improve students' understanding of emerging diseases, specifically about how to study and prevent emerging infectious diseases to protect public health. Future proposed improvements include the development of a complete elearning package for students and academics for teaching these topics in collaboration with Universities from Spain and practising Biomedical Scientists from the National Health Service. These resources will be accessible throughout 2018.
\end{abstract}

Keywords: Curriculum modifications, teaching parasitology, infectious diseases, undergraduate students, biomedical science.

\section{INTRODUCTION}

Recent outbreaks threatening public health involving contaminated water or food with different microorganisms such as microsporidia or Cyclospora in Europe [1,2] or the unprecedented 2014-2016 Ebola epidemic in West Africa have highlighted the relevance of teaching parasitology and infectious diseases to future biomedical scientists. The BSc Biomedical Science (BMS) programme at De Montfort University (DMU, UK) [3] is accredited by the Institute of Biomedical Science (IBMS). However, the dedicated time to study these topics was very little, limited to two 15 credit modules focused on general/medical microbiology. In general, our BMS students have requested a more clinical approach in their programme and have welcomed the introduction of clinical case studies and 
workshops related to real-life scenarios during the 2016/17 course. The introduction of these teaching activities form part of a series of important modifications that have been undertaken since 2016 to ensure that our graduates receive comprehensive knowledge in parasitology/infectious diseases following the subject-specific threshold standards described by the Quality Assurance Agency (QAA, 2015 [4]). We have also sought relevant advice by parasitologists at the Faculty of Pharmacy at the Universidad San Pablo CEU (CEU, Madrid, Spain) [5], particularly with the development of the case studies. A description of the implemented plan to improve the teaching in parasitology and infectious diseases is provided below in conjunction with an analysis of student satisfaction and the identification of possible markers that indicate acquisition of knowledge and clinical skills in these areas.

\section{METHODOLOGY}

The main aim of this study was to investigate if the comprehensive curriculum modifications performed in the BMS programme at DMU have been translated in an improvement in the knowledge of parasitology and infectious diseases in our BMS students.

\subsection{Curriculum changes}

Curriculum changes and the introduction of different teaching approaches were performed in the BMS curriculum, targeting specifically the syllabus of two key modules: "Basic Microbiology" (level 4, 15 credits) and "Medical Microbiology" (level 6, 15 credits). Briefly, the following changes were undertaken:

\subsubsection{Changes undertaken in the Basic Microbiology module}

"Basic Microbiology" was expanded to 30 credits and re-named "Basic Microbiology for Biomedical Science". New lectures were introduced on the following topics: virus, fungi, helminths and emerging infectious diseases. Another significant improvement was an increment in the number of lectures related to parasitology, increasing them from 1 onto 3 . The list of lectures/topics delivered in 2016/17 can be found in the Table 1 below.

Table 1. List of lectures of "Basic Microbiology for Biomedical Science" for 2016/17.

\begin{tabular}{|l|}
\hline Introduction to the module \\
\hline Bacterial cell structure; difference between prokaryote and eukaryote; staining methods \\
\hline Taxonomy of microbes (Parts I \& II) \\
\hline Medically important Gram negative bacteria (Parts I \& II) \\
\hline Spirochetes \\
\hline Medically important Gram positive bacteria-non-spore forming \\
\hline Medically Important Gram positive bacteria-spore forming \\
\hline Microbial growth \\
\hline Microbial interactions with humans - normal microflora \\
\hline Microbial genetics - bacterial genetics (Parts I \& II) \\
\hline Microbial genetics - genetic function (Parts I \& II) \\
\hline Microbial evolution \\
\hline Antimicrobials and antimicrobial drug resistance (Parts I \& II) \\
\hline Antibiotic susceptibility testing (Parts I \& II) \\
\hline Infection detection methods and infection control \\
\hline Sterilisation and disinfection \\
\hline Viruses (Parts I \& II) \\
\hline Mycology (Parts I \& II) \\
\hline Parasites (Parts I, II \& III) \\
\hline Emerging Infectious Diseases \\
\hline
\end{tabular}


A new lecture related to emerging infectious diseases was designed and introduced by a biomedical scientist registered with the UK Health and Care Professions Council (HCPC) [5] that worked in the UK response to the Ebola outbreak in West Africa in 2015 [6]. The HCPC is the UK regulatory body that certifies that health and care professionals such as biomedical scientists meet training, professional skills, behaviour and health standards to deliver their professions [7]. Registration is a necessary requirement for health and care professionals that want to work in the UK.

\subsubsection{Changes undertaken in the "Medical Microbiology" module}

Contrarily to Basic Microbiology, only a few new topics/lectures were introduced in the final year module of "Medical Microbiology", which were: emerging diseases, Ebola, Cyclospora and free-living amoeba and Trypanosomes. However, to make the module more interactive, clinical case studies and a highly specialised training/workshop was introduced in the module.

The parasitology mini-case studies were created to improve the limited clinical skills of final year BMS students in collaboration with reputed parasitologists from CEU. The structure of the mini-case studies was as follows, during the new lectures noted above, students were provided with different slides collected from the Laboratory Identification of Parasitic Diseases of Public Health Concern (DPDx) (CDC, 2017 [8]) in conjunction with a short medical history. Students, by peer group interaction, provided a possible "diagnosis" for each clinical case based on the clinical features presented and microscopic slides provided. Students needed to reflect on their knowledge and from the information provided during the lectures and quickly search for information through web-enabled mobiles, laptops or tablets to propose possible diagnoses. Reflection is an essential learning tool for developing aspects such autonomous working, critical and analytical thinking and integration of theory with practice [9]. Although preliminary, our teaching group has also recently observed that reflection may help students acquire clinical skills (unpublished data).

In relation to the training regarding an outbreak scenario, we delivered a research-led workshop (totalling 3 hours, practical element 1 hour long) which consisted of the development of an intervention programme for an outbreak due to the emerging pathogen Category A Crimean-Congo Haemorrhagic Fever virus [10]. We selected this virus as it is threatening countries in Western Europe [11], including the UK [12]. This research-led training was based on a successful novel teaching experience created by our team [13] and was aimed to assure the relevance that biomedical scientists have as key health professionals in any first response team in the aftermath of a biological incident or an outbreak of infection. A more detailed description of this workshop will be published in the next few months, which can be found in Peña-Fernández et al. (2017 [14]).

\subsubsection{Student feedback}

We used qualitative and quantitative approaches to gain information about the changes performed in both modules during the course 2016/17. Three feedback questionnaires were used, interim and final module level feedback (MLF) surveys, which are on-line questionnaires that have a Likert scale and free form response questions, and a specific feedback-questionnaire to assess the training delivered in Medical Microbiology. The two MLF questionnaires were made available to all students enrolled in both modules through Blackboard and an email link (196 students were enrolled in the first year and 121 were studying in their final year); students completed the interim MLF survey during the $4^{\text {th }}$ week of November 2016 and the final MLF survey was opened during the first two weeks of May 2017 (the academic course started on the $3^{\text {rd }}$ of October 2016 and finished in June 2017).

The validated feedback questionnaire was based on a previous teaching experience and also had Likert and free form questions. It was completed during the last 5 minutes of the workshop. Ethical approval was provided by the Research Ethics Committee at DMU (Ref. 1729).

\section{RESULTS \& DISCUSSION}

Students highlighted high levels of engagement in both modules, specifically in the training provided in Medical Microbiology. However, the most notable increase in student satisfaction was detected in Basic Microbiology module (level $4 ; n=196$ ). Thus, student satisfaction increased from $20 \%$ in the $2015 / 16$ academic year to $64 \%$ in the current academic session (percentage responses for agree and strongly agree were considered together; Fig. 1). A reduction in the number of students dissatisfied was also recorded for Medical Microbiology (level $6 ; n=120$ ) in this period, from $20 \%$ to $7.4 \%$ (percentages responses for disagree and strongly disagree were considered together; Fig. 2). 




Figure 1. Student satisfaction (\%) for Basic Microbiology per academic year. Absence of a Likert category indicates no responses for that category.

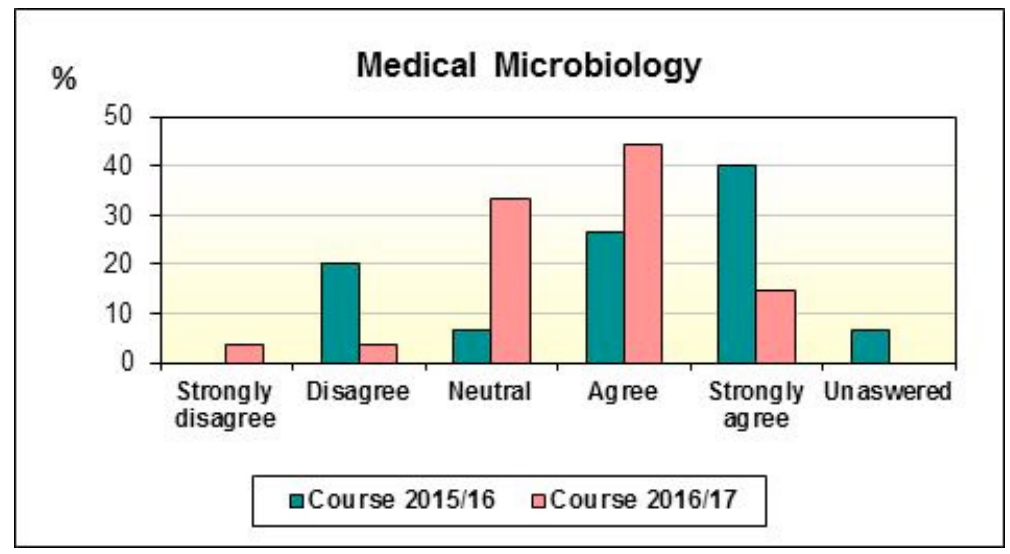

Figure 2. Student satisfaction (\%) for Medical Microbiology per academic year. Absence of a Likert category indicates no responses for that category.

The final MLF for Basic Microbiology also highlights a high level of student satisfaction in areas that are key for students such as feedback and marking. Thus, $95 \%$ ( $41 \%$ definitely agree, $54 \%$ agree) of students have highlighted that this first year module provided them with opportunities to apply what they learnt; $94 \%$ ( $56 \%$ definitely agree, $38 \%$ agree) considered that the feedback provided was clear; and $100 \%$ (56\% definitely agree, $44 \%$ agree) indicated that marking and assessment for this module was fair.

In relation with the mini-case studies introduced in Medical Microbiology, students have highlighted in the interim and final MLF that they "improved my understanding" and were "engaging".

A more comprehensive analysis of the validated feedback questionnaire used to evaluate the novel workshop introduced in Medical Microbiology and will be published in Peña-Fernández et al. (2017) [14]. However, the initial analysis and impressions of this survey are reported briefly here. Thus, $90 \%$ and $77.5 \%$ (Figs. 3-4) of final year students were satisfied and enjoyed the novel workshop to respond to an outbreak of infection affecting the UK following evidence-based public health methodology. 
Students reported acquisition of knowledge, particularly related with prevention and preparedness in the aftermath of an outbreak of infection (Fig. 5) and how to investigate and emerging disease (Fig. 6).

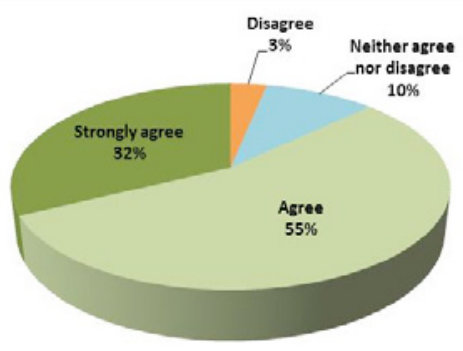

Learnt public health prevention/preparedness

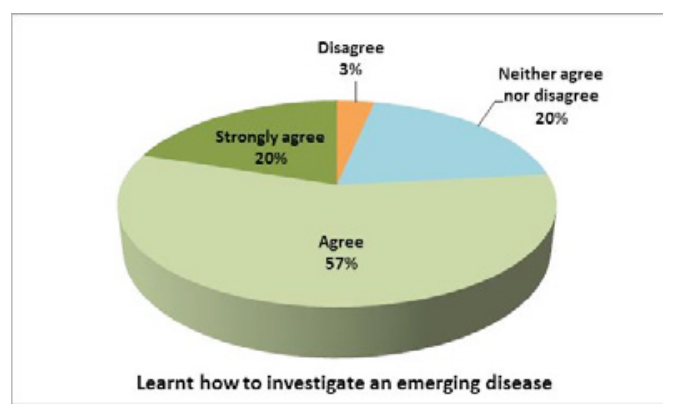

Figure 6. Student learnt (\%) on investigating an emerging disease. Absence of a Likert category indicates no responses for that category.



.
Figure 5. Student learnt (\%) on prevention \& preparedness. Absence of a Likert category indicates no responses for that category.



Satisfied with the workshop provided
Figure 4. Student enjoyment (\%) on the workshop. Absence of a Likert category indicates no responses for that category.

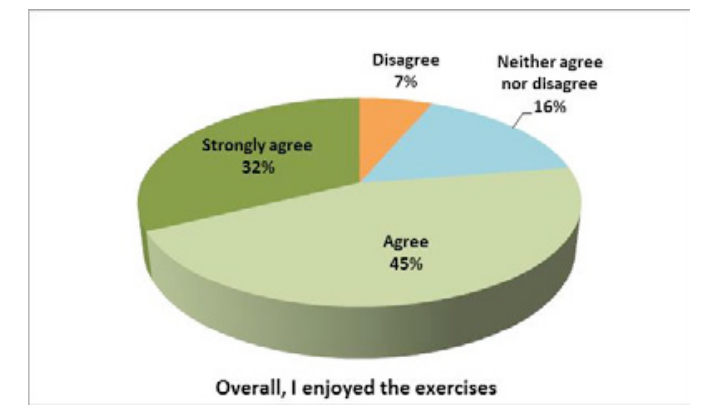

(1)

Figure 3. Student satisfaction (\%) on the workshop. responses for that category.

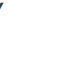

\section{CONCLUSIONS}

Although these results should be considered as preliminary, we conclude that the initial changes undertaken in the BMS programme at DMU described in this paper could improve students' knowledge and understanding of parasitology and infectious diseases, such as for example prevention of transmission to protect public health. Thus this short workshop enabled the transmission of knowledge related to infectious diseases. Moreover, the use of mini-case studies might have facilitated the acquisition of clinical skills in our students, as we observed a progressive understanding and faster resolution of these mini-case studies throughout the course, although more studies are needed.

Future proposed improvements include the development of a complete e-learning package for students and academics for teaching these topics in collaboration with Universities from Spain and practising Biomedical Scientists from the National Health Service, which will become available in 2018.

\section{REFERENCES}

[1] Decraene V, Lebbad M, Botero-Kleiven S, Gustavsson AM, Löfdahl M. First reported foodborne outbreak associated with microsporidia, Sweden, October 2009. Epidemiol Infect 2012; 140(3):519-27.

[2] Nichols GL, Freedman J, Pollock KG, et al. Cyclospora infection linked to travel to Mexico, June to September 2015. Euro Surveill 2015; 20(43). doi: 10.2807/1560-7917.ES.2015.20.43.30048. 
[3] BSc Biomedical Science programme website. Available at the DMU website:

http://www.dmu.ac.uk/study/courses/undergraduate-courses/biomedical-science-bsc-honsdegree/biomedical-science-bsc-hons.aspx [accessed 12/09/2017].

[4] QAA. Subject Benchmark Statement: Biomedical Sciences, 2015. Available at: http://www.qaa.ac.uk/publications/information-and-

guidance/publication?PubID=3013\#.Wbf4Xk2Wxfw [accessed 12/09/2017].

[5] Parasitology research group. Universidad San Pablo CEU. Available at: http://www.uspceu.com/es/investigacion/grupos-investigacion/index.aspx [accessed 12/09/2017].

[6] Peña-Fernández A., Choi EML. Novel methods of teaching evidence-based medicine and public health: experience from the field during the Ebola outbreak. ICERI2016 Proceedings; pp. 43274335.

[7] HCPC website. Available at: http://www.hcpc-uk.co.uk/aboutus/ [accessed 15/09/2017].

[8] CDC (Centres for Disease Control and Prevention). Laboratory Identification of Parasitic Diseases of Public Health Concern (DPDx); Monthly Case Studies 2017. Available at: https://www.cdc.gov/dpdx/monthlyCaseStudies/2016/index.html [accessed 15/09/2017].

[9] Quintanilla G., Copa-Patiño JL., Guerrero A., González-Santander M., Hernández N., Arias MS., Domínguez MI., Peña MA., Evans MD., Peña-Fernández A. Reflective practice applications: "Guided Weekly Reflection Papers" extended from Alcalá University (Spain) to De Montfort University (UK). EDULEARN16 Proceedings 2016; 6250-6256.

[10] National Institute of Allergy and Infectious Diseases. NIAID Emerging Infectious Diseases/Pathogens website. Available at: https://www.niaid.nih.gov/research/emerginginfectious-diseases-pathogens

[11] England ME, Phipps P, Medlock JM, Atkinson PM, Atkinson B, Hewson R, Gale P. Hyalomma ticks on northward migrating birds in southern Spain: Implications for the risk of entry of Crimean-Congo haemorrhagic fever virus to Great Britain. Journal of Vector Ecology 2016; 41(1):128-34.

[12] Hansford KM, Medlock JM, Atkinson B, Santos-Silva MM. Importation of a Hyalomma Iusitanicum tick into the UK on a dog. Vet Rec 2016; 179(16):415.

[13] Peña-Fernández A., Zinsky R., Choi E., Broadbent AJ. Developing training to prepare human health science students to face biological incidents. INTED2017 Proceedings 2017; pp. 47074714.

[14] Peña-Fernández A, Escalera B, Peña MÁ. Evaluating basic training for prevention and response to biological incidents. In: Research in university teaching. Designing the future from educational innovation. Editorial Octaedro. ISBN: 978-84-9921-935-6. In press. 